\title{
Anxiety and Its Association with Preparation for Future Specialty: A Cross-Sectional Study Among Medical Students, Saudi Arabia
}

This article was published in the following Dove Press journal: Journal of Multidisciplinary Healthcare

\author{
Nouf A AIShamlan (D) \\ Reem S AIOmar' \\ Malak A Al Shammari (D) \\ Reem A AIShamlan (D) ${ }^{2}$ \\ Abeer A AIShamlan ${ }^{2}$ \\ Abdulaziz M Sebiany (D) \\ 'Department of Family and Community \\ Medicine, Imam Abdulrahman Bin Faisal \\ University, Dammam, Saudi Arabia; \\ ${ }^{2}$ College of Medicine, Imam Abdulrahman \\ Bin Faisal University, Dammam, Saudi \\ Arabia
}

Background: Anxiety disorders are a significant global health concern with destructive morbidity and mortality. Medical school is a stressful environment worldwide. This study measures the prevalence of anxiety symptoms among clinical-year medical students in Saudi Arabia. As well as to explore its association with students' sociodemographic factors, academic performance, issues experienced by them during the study of medicine, and their perceived readiness for their future specialties.

Methods: The generalized anxiety disorder (GAD-7) tool along with a sociodemographic questionnaire was distributed to 523 clinical-year medical students (fourth, fifth and sixth years) from the Imam Abdulrahman Bin Faisal University, Saudi Arabia, in this crosssectional study. Data analysis was performed with SPSS version 23 and it included the ChiSquare or Fisher's exact tests for bivariate analysis, and the multivariable logistic regression to account for confounders.

Results: The prevalence of anxiety symptoms as measured by the GAD-7 was found to be $31.7 \%$. Of these, $14.3 \%$ had severe symptoms. Only $4.4 \%$ students went to a healthcare professional and were diagnosed with psychiatric problems. Logistic regression analysis revealed that the odds of anxiety was higher among females and students who had perceived psychological problems. However, students' grade point average (GPA) and perceived readiness for their future specialty were not statistically significant with anxiety symptoms. Conclusion: Anxiety was highly prevalent among clinical-year medical students included in this study. This urges periodic mental health screening, proper diagnosis of high-risk individuals in medical schools, and early interventions through confidential access to mental health services.

Keywords: prevalence, generalized anxiety disorder, medical students, Saudi

\section{Introduction}

Mental health is an essential component of the World Health Organization's (WHO) definition of health. ${ }^{1}$ Anxiety disorders are common mental health problems and they are associated with high morbidity and mortality. Around 264 million people were living with anxiety disorders according to a report released by the WHO in $2017 .^{2}$ Patients with anxiety symptoms present with excessive worry about several events or activities (such as work or school performance) that are difficult to control, and which are associated with at least three of the following symptoms: restlessness, irritability, fatigue, sleep disturbance, difficulty in concentration, and muscle aches. ${ }^{3}$
Correspondence: Nouf A AIShamlan Department of Family and Community Medicine, Imam Abdulrahman Bin Faisal University, Dammam, Saudi Arabia Tel +00966504901406

Email nashamlan@iau.edu.sa 
Studies have reported that the prevalence of anxiety symptoms in medical students is higher as compared with non-medical students and the age-matched general population. ${ }^{4,5}$ A large multicenter study was conducted across 17 Canadian schools of medicine that involved medical students from all years and compared them with age-matched controls from the general population. Results showed that the prevalence of diagnosed anxiety disorders were higher among medical students $(9.6 \%)$ than the agematched general population (4.0\%). Moreover, students in clinical years experienced anxiety disorders more than students in the preclinical years. ${ }^{6}$

Medical training is the transitional phase from high school to a new environment that involves adult learning with minimal supervision. ${ }^{7}$ In Saudi Arabia, studying medicine usually takes six years. During these years, students obtain knowledge, skills, and attitudes to prepare them for future professions. ${ }^{8}$ Nevertheless, the training demands could affect the students' mental and physical health, and consequently their academic performance. Moreover, the environment in medical colleges is highly competitive, since students are looking for opportunities in postgraduate training and future jobs, which could be an additional trigger for mental illness. ${ }^{9}$ Additionally, the transition from preclinical to clinical years in medical college could be anxiogenic and stressful to students since they are exposed to real patients and adverse outcomes like death. ${ }^{7}$

In 2019, a meta-analysis reported that the prevalence of anxiety among medical students worldwide was $33.8 \%$ $(95 \%$ Confidence Interval $[\mathrm{CI}]=29.2-38.7) .{ }^{10}$ Similarly, a cross-sectional study carried out in 2015 at Fayoum University in Egypt among 442 medical students using the Depression, Anxiety, and Stress Scale-21 (DASS-21) tool revealed that the prevalence of anxiety was $64.3 \%$. Moreover, female students, those older than 20 years, and single students had higher anxiety scores. ${ }^{11}$ A crosssectional study conducted among 350 medical students in a university in Bahrain using Beck's Anxiety Inventory (BAI) instrument showed that $51 \%$ of the students had anxiety symptoms. Anxiety was high among female students as well as in students who had repeated a year in medical college. ${ }^{7}$ In Lebanon, a cross-sectional study was conducted among 176 medical students at the American University of Beirut Medical Centre using the Generalized Anxiety Disorder (GAD-7) scale reported that $22.7 \%$ of students had anxiety symptoms. ${ }^{12}$ A study conducted at the Alfaisal University, Riyadh, Saudi Arabia between
2012 and 2013 had measured the prevalence of anxiety and stress among medical students before examinations and during regular classes. Medical students $(\mathrm{N}=442)$ from both phases: basic (first and second levels) and clerkship (third, fourth, and fifth levels) were included. The study revealed that while the prevalence of anxiety and stress before examinations were $63 \%$ and $41 \%$, respectively; it reduced to $47 \%$ and $30 \%$, respectively, after examinations. ${ }^{9}$ In the Kingdom of Saudi Arabia (KSA), after graduation, medical students have different options such as joining local postgraduate residency or international programs; master's and doctoral programs in preclinical fields; or working as general practitioners in primary care centres. Local residency programs are provided by the Saudi Commission for Health Specialties (SCFHS) and some universities in the KSA. Local programs are highly competitive. While the selection criteria are annually updated, usually it depends on the curriculum vitae (CV), with higher points granted to students that have participated in researches, grade point average (GPA), and the Saudi Medical Licensing Exam (SMLE) score. ${ }^{13} \mathrm{~A}$ few studies have been carried out to assess anxiety symptoms among medical students in KSA, and no prior study has been conducted to evaluate the association between medical students' anxiety and their preparation for future specialties. Hence, this study aimed to estimate the prevalence of anxiety symptoms among clinical-year medical students in the Imam Abdulrahman Bin Faisal University (IAU), Eastern Province, KSA, and determine possible associations with their sociodemographic characteristics, academic factors, previous problems experienced by them during the study of medicine, and their readiness for future specialties.

\section{Methods}

This cross-sectional study was conducted during 2019 at the IAU, in Saudi Arabia's Eastern Province. The target population comprised all medical students in their fourth, fifth, and sixth clinical years. Assuming that the prevalence of anxiety among students was $18 \%,{ }^{14}$ with a precision of $2 \%$ and an alpha level of 0.05 ; the minimum required sample size was calculated as 484 students using Epi info 7.0. The sample size was inflated to 550 to overcome the potential missing data.

\section{Data Collection}

Students in each of the three academic years were divided into two groups based on their gender, which gave a total of six groups. The students' ID list that the Department of 
Students Affairs provided for each group was taken as the sampling frame $(\mathrm{N}=735)$. Thereafter, the simple random sampling technique was conducted using a computergenerated random numbers to select participants. Students whose ID numbers were selected through the sampling technique, were approached individually with a paper-based questionnaire in English, since the educational language in the college of medicine is English. The IAU's Institutional Review Board (IRB) committee approved the study with IRB number: IRB-UGS-2019-01-147. The study was conducted according to the principles of the Declaration of Helsinki. All the participants provided their written consent and participation in the study was voluntary. The researcher explained the study's purpose to the participants and reassured them that it would not have any negative impact on them. They were also assured of the data's confidentiality and that it would be used only for research purposes.

\section{Data Collection Tool}

The data were collected using a self-administered questionnaire that contained questions on the sociodemographic characteristics, academic factors such as the GPA, perception of problems experienced by students since admission to university, and their perceived readiness for specialties (see Table 1). The GPA in KSA is based on the 5-points system similar to the US. The questionnaire also contained a subsection that included the Generalized Anxiety Disorder (GAD -7) tool.

The GAD-7 questionnaire is a valid and efficient tool for screening for anxiety and assessing its severity in both clinical practice and research. ${ }^{15} \mathrm{~A}$ seven-item questionnaire asked participants how often during the previous two weeks, they had been bothered by each symptom. Each item had four possible response options: 0 corresponding to "not at all," 1 to "several days," 2 to "more than half of the days," and 3 to "nearly every day." The GAD-7 total score ranged from 0-21. Scores of 0-4, 5-9, 10-14, and 15-21 represented cut offs for minimal, mild, moderate, and severe anxiety, respectively. Many authors used this instrument to measure rates of anxiety symptoms in medical students. ${ }^{5,16}$ A score of 10 or greater on the GAD-7 had a good sensitivity $(89 \%)$ and specificity $(82 \%)$ cut-off to identify cases of anxiety. ${ }^{12,15}$ Therefore, in the current study, GAD-7 scores of less than 10 indicated no anxiety, while scores of 10 or above were considered indicative of anxiety.
Table I Sociodemographic, Academic Characteristics, and Profile of Problems Experienced by the Participating Medical Students During Study of Medicine $(\mathrm{N}=523)$

\begin{tabular}{|c|c|c|}
\hline Characteristics & Number & $\%$ \\
\hline \multicolumn{3}{|l|}{ Age group (years) } \\
\hline $20-21$ & 93 & 17.8 \\
\hline $22-23$ & 360 & 68.8 \\
\hline$\geq 24$ & 70 & 13.4 \\
\hline \multicolumn{3}{|l|}{ Sex } \\
\hline Male & 237 & 45.3 \\
\hline Female & 286 & 54.7 \\
\hline \multicolumn{3}{|l|}{ Level in the medical college } \\
\hline Fourth year & 184 & 35.2 \\
\hline Fifth year & 194 & 37.1 \\
\hline Sixth year & 145 & 27.7 \\
\hline \multicolumn{3}{|l|}{ Marital status } \\
\hline Single & 444 & 84.9 \\
\hline Married & 71 & 13.6 \\
\hline Divorced & 7 & 1.3 \\
\hline Widowed & I & 0.2 \\
\hline \multicolumn{3}{|l|}{ Living arrangements } \\
\hline With parents & 366 & 70.0 \\
\hline With spouse & 49 & 9.4 \\
\hline With relative & 20 & 3.8 \\
\hline Alone & 24 & 4.6 \\
\hline With friend & 5 & 0.9 \\
\hline Student accommodation & 59 & 11.3 \\
\hline \multicolumn{3}{|l|}{ GPA out of 5} \\
\hline$\leq 3.50$ & 36 & 6.9 \\
\hline $3.51-4.00$ & 192 & 36.7 \\
\hline $4.01-4.50$ & 219 & 41.9 \\
\hline$>4.50$ & 76 & 14.5 \\
\hline \multicolumn{3}{|l|}{$\begin{array}{l}\text { Ever failed in any module during study of } \\
\text { medicine }\end{array}$} \\
\hline Yes & 12 & 2.3 \\
\hline No & 511 & 97.7 \\
\hline \multicolumn{3}{|l|}{ Did you choose you future specialty? } \\
\hline Yes & 315 & 60.2 \\
\hline No & 191 & 36.5 \\
\hline Not willing to have any & 17 & 3.3 \\
\hline \multicolumn{3}{|l|}{ Did you prepare your CV? } \\
\hline Yes & 99 & 18.9 \\
\hline No & 305 & 58.3 \\
\hline Not sure & 119 & 22.8 \\
\hline \multicolumn{3}{|l|}{ Did you participate in a research project? } \\
\hline Yes & 271 & 51.8 \\
\hline No & 252 & 48.2 \\
\hline
\end{tabular}

(Continued) 
Table I (Continued).

\begin{tabular}{|l|l|l|}
\hline Characteristics & Number & $\%$ \\
\hline Are you ready for your future specialty? & & \\
Strongly agree & 38 & 7.3 \\
Agree & 100 & 19.1 \\
Neutral & 250 & 47.8 \\
Disagree & 66 & 12.6 \\
Strongly Disagree & 69 & 13.2 \\
\hline Family problems during study of medicine & & \\
Yes & 142 & 27.2 \\
No & 381 & 72.8 \\
\hline Financial problems during study of medicine & & \\
Yes & 108 & 20.7 \\
No & 415 & 79.3 \\
\hline Social problems during study of medicine & & \\
Yes & 139 & 26.6 \\
No & 384 & 73.4 \\
\hline Psychological issues during study of medicine & & \\
Yes & 112 & 21.4 \\
No & 411 & 78.6 \\
\hline Diagnosed with medical problems during study of & & \\
medicine & & \\
Yes & 88 & 16.8 \\
No & 435 & 83.2 \\
\hline Diagnosed with psychiatric problems during & & \\
study of medicine & 23 & 4.4 \\
Yes & 500 & 95.6 \\
No & & \\
\hline
\end{tabular}

Abbreviations: GPA, grade point average; CV, curriculum vitae.

Three experts revised the questionnaire's content validity; and thereafter, it was approved by all of them. To review the clarity of the questionnaire, a pilot study was conducted on 40 medical students, who had not been included in the main sample.

\section{Statistical Analysis}

Data analysis were performed using the SPSS version 23 (Armonk, NY IBM Corp., USA). Descriptive statistics were used to present the data in tables and a bar chart. Categorical variables were presented as frequency and percentages, and compared using the chi-square test or Fisher's exact test, as appropriate. Continuous variables were reported as mean \pm standard deviation (SD). A multivariable logistic regression analysis was performed to identify independent predictors of anxiety. Unadjusted odds ratios (OR) and adjusted odds ratios (aOR) with their
95\% CI were estimated using the full model fit. Variables were selected as candidates for the logistic regression models based on known determinants of anxiety identified in the literature and having a bivariate $p$-value of $<0.2$. In all instances, a two-sided p-value $<0.05$ was considered statistically significant.

\section{Results \\ Characteristics of the Respondents}

A total of 523 respondents ( $95.1 \%$ response rate) completed the surveys. Of these, $360(68.8 \%)$ were in the $22-23$ years age group, and the mean ( \pm SD) age was $22.4 \pm 0.96$. In addition, 286 (54.7\%) were females. Overall, 194 (37.1\%) were in their fifth year of study and $444(84.9 \%)$ were single. The respondents living with their parents comprised $70.0 \%$ of the sample. The GPA of $219(41.9 \%)$ students fell between 4.01 and 4.50 , while only $12(2.3 \%)$ had failed in the previous module. Of the students, $315(60.2 \%)$ had chosen their future specialty, only 99 (18.9\%) had prepared their CVs, and 271 (51.8\%) had previously participated in research projects. Around half of the participants $(n=250)$ reported themselves as being neutral to their future specialties. Around 142 (27.2\%) respondents had family problems, 108 (20.7\%) had financial problems, and 139 (26.6\%) had social problems. In addition, 112 (21.4\%) respondents reported psychological issues; and $88(16.8 \%)$ and 23 (4.4\%) were diagnosed with medical and psychiatric problems, respectively, during their study of medicine. Table 1.

\section{Levels of Anxiety Symptoms Among the Respondents}

Among the respondents, 217 (41.5\%) had minimal anxiety, $140(26.8 \%)$ had mild anxiety, 91 (17.4\%) had moderate anxiety, and $75(14.3 \%)$ had severe anxiety according to the GAD-7 questionnaire's different anxiety severity cutoffs. Overall, 166 (31.7\%) respondents had anxiety based on a score of 10 or greater in the GAD-7 questionnaire.

The distribution of the levels of anxiety symptoms according to gender are shown in Figure 1. As compared to men, a higher proportion of women had severe anxiety $(\mathrm{p}<0.001)$.

The respondents' levels of anxiety symptoms according to their sociodemographic, academic characteristics, and problems experienced by students during study of medicine are shown in Table 2. There were no significant differences based on their age groups $(\mathrm{p}=0.34)$, marital status $(p=0.87)$, and living arrangements $(p=0.44)$. Moreover, 


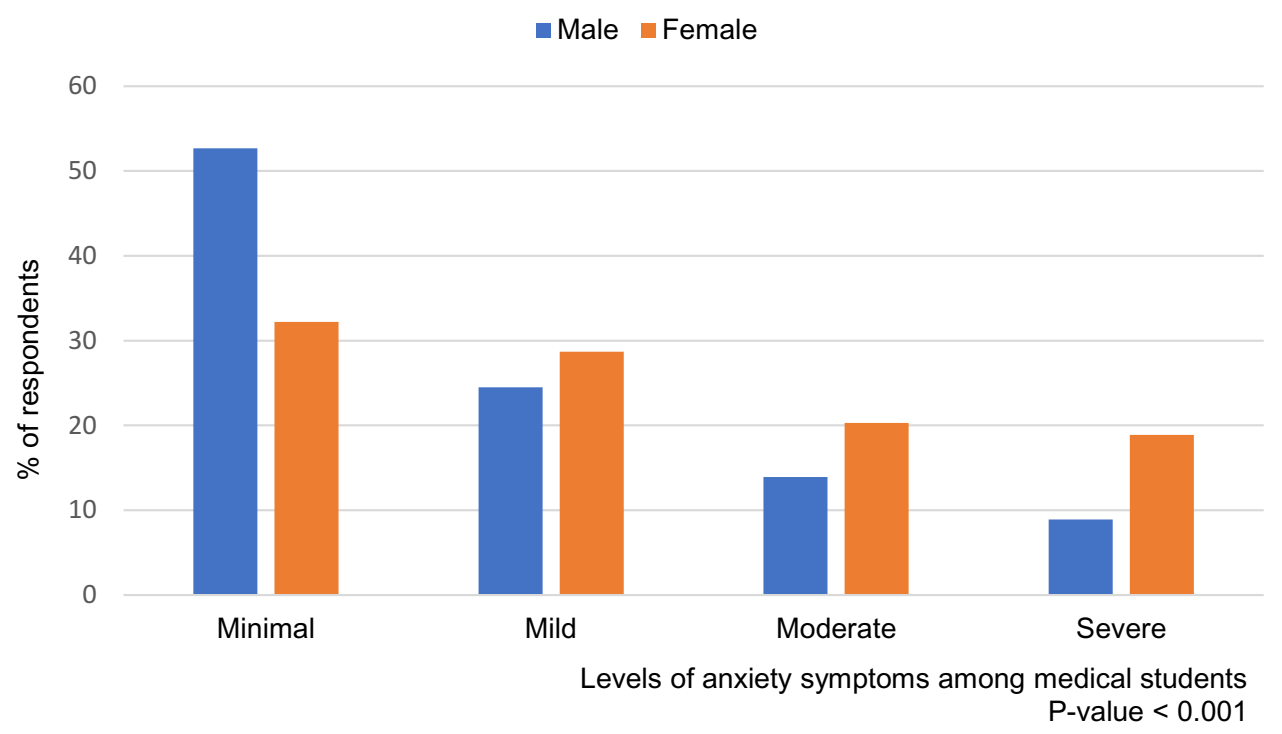

Figure I Distribution of anxiety levels of the participating medical students according to their gender $(\mathrm{N}=523)$.

the levels of anxiety among females was $39.2 \%$ as compared with $22.8 \%$ among males $(\mathrm{p}<0.001)$; and the proportion of the respondents with anxiety varied according to their level in medical college $(p=0.006)$ and the most affected level with anxiety was the fourth-year level (40.2\%). Respondents with a GPA of $\leq 3.50$ had a higher rate of anxiety than those with a higher GPA $(p=0.006)$. The proportion of respondents with anxiety was significantly associated with their readiness for future specialty training $(\mathrm{p}<0.001), 53.6-37.9 \%$ of students who were strongly disagree and disagree that they were ready for future specialty, respectively, had anxiety. The association between anxiety and students' participation in the research project was not statistically significant $(p=0.35)$. Overall, as compared to respondents who had not experienced problems, the levels of anxiety were higher among those with financial problems $(41.7 \%$ vs $29.2 \% ; p=0.01)$, social problems $(43.2 \%$ vs $27.6 \%, p=0.001)$, psychological issues $(55.4 \%$ vs $25.3 \% ; \mathrm{p}<0.001)$, and medical problems $(44.3 \%$ vs $29.2 \% ; \mathrm{p}=0.005)$.

\section{Factors Associated with Anxiety Symptoms}

Table 3 presents the findings of the multivariable logistic regression analysis of predictors of anxiety symptoms among the respondents. The independent predictors of anxiety were female sex $(\mathrm{OR}=1.7,95 \%$ CI $1.1-2.7)$ and having psychological issues during their study of medicine $(\mathrm{OR}=3.1,95 \%$ CI 1.8-5.2); whereas the odds of anxiety were not associated with students' perceived readiness for specialties and GPA.

\section{Discussion}

The current study showed a high prevalence of anxiety symptoms among the examined medical students. Several studies worldwide have also examined the prevalence of anxiety among medical students. However, differences in participants' characteristics, cultures, study instruments, and methodology makes comparisons between different studies inaccurate or difficult. The studies on this issue are few in the Middle East. We found that $31.7-14.3 \%$ of medical students had anxiety and severe symptoms, respectively. This finding was higher than a previous investigation in Portugal using the Hospital Anxiety and Depression Scale (HADS), which had reported that $21.5 \%$ of college students had anxiety symptoms but the prevalence was higher among medical students than other college students. ${ }^{4}$ In Lebanon, Talih et al used the GAD-7 tool which revealed that $22.7 \%$ of medical students had anxiety symptoms. ${ }^{12}$ Mousa et al surveyed 126 residents and 336 medical students in New York, using the GAD-7 instrument. Its results revealed that $15.9 \%$ of the residents from different specialties and $20.3 \%$ of students had anxiety. ${ }^{5}$ In 2017, using the Beck Anxiety Scales, one Pakistani study reported that $19 \%$ of its medical students had moderate to severe anxiety symptoms. ${ }^{17}$ Our study's results were lower than that reported by AlBahhawi et al in Jazan University, KSA, where $65.7 \%$ of the students had anxiety symptoms based on data collected using the 
Table 2 Levels of Anxiety Symptoms According to the Sociodemographic and Academic Characteristics of the Participating Medical Students and Problems Experienced by Them During Study of Medicine ( $\mathrm{N}=523)$

\begin{tabular}{|c|c|c|c|c|}
\hline \multirow[t]{2}{*}{ Characteristics } & \multicolumn{2}{|l|}{ Anxiety } & \multirow[t]{2}{*}{$X^{2}$} & \multirow[t]{2}{*}{ P-value } \\
\hline & $\begin{array}{l}\text { No, n }(\%) \\
\text { (GAD-7score <10) }\end{array}$ & $\begin{array}{l}\text { Yes, n (\%) } \\
\text { (GAD-7score } \geq 10)\end{array}$ & & \\
\hline Age group (years) & & & 2.17 & 0.34 \\
\hline $20-21$ & $59(63.4)$ & $34(36.6)$ & & \\
\hline $22-23$ & $246(68.3)$ & $114(31.7)$ & & \\
\hline$\geq 24$ & $52(74.3)$ & $18(25.7)$ & & \\
\hline Sex & & & 16.04 & $<0.001$ \\
\hline Male & $183(77.2)$ & $54(22.8)$ & & \\
\hline Female & $174(60.8)$ & $112(39.2)$ & & \\
\hline Level in the medical college & & & 10.16 & 0.006 \\
\hline Fourth year & $110(59.8)$ & $74(40.2)$ & & \\
\hline Fifth year & 145 (74.7) & $49(25.3)$ & & \\
\hline Sixth year & $102(70.3)$ & $43(29.7)$ & & \\
\hline Marital status & & & 0.70 & 0.87 \\
\hline Single & $301(67.8)$ & $143(32.2)$ & & \\
\hline Married & $50(70.4)$ & $21(29.6)$ & & \\
\hline Divorced & $5(7 \mid .4)$ & $2(28.6)$ & & \\
\hline Widowed & I $(100)$ & $0(0)$ & & \\
\hline Living arrangements & & & 4.78 & 0.44 \\
\hline With parents & $257(70.2)$ & $109(29.8)$ & & \\
\hline With spouse & $34(69.4)$ & $15(30.6)$ & & \\
\hline With relative & $10(50.0)$ & $10(50.0)$ & & \\
\hline Alone & $16(66.7)$ & $8(33.3)$ & & \\
\hline With friend & $3(60.0)$ & $2(40.0)$ & & \\
\hline Student accommodation & $37(62.7)$ & $22(37.3)$ & & \\
\hline GPA out of 5 & & & 12.36 & 0.006 \\
\hline$\leq 3.50$ & I8 (50.0) & $18(50.0)$ & & \\
\hline $3.5 I-4.00$ & $145(75.5)$ & $47(24.5)$ & & \\
\hline $4.01-4.50$ & $148(67.6)$ & $71(32.4)$ & & \\
\hline$>4.51$ & $46(60.5)$ & $30(39.5)$ & & \\
\hline Ever failed in any module during study of medicine & & & 0.56 & 0.46 \\
\hline Yes & $7(58.3)$ & $5(4 I .7)$ & & \\
\hline No & $350(68.5)$ & 161 (3I.5) & & \\
\hline Did you choose you future specialty? & & & 3.94 & 0.14 \\
\hline Yes & $220(69.8)$ & $95(30.2)$ & & \\
\hline No & $129(67.5)$ & $62(32.5)$ & & \\
\hline Not willing to have any & $8(47.1)$ & $9(52.9)$ & & \\
\hline Did you prepare your CV? & & & 0.01 & 0.99 \\
\hline Yes & $68(68.7)$ & $31(31.3)$ & & \\
\hline No & $208(68.2)$ & $97(31.8)$ & & \\
\hline Not sure & $81(68.1)$ & $38(31.9)$ & & \\
\hline Did you participate in a research project? & & & 0.89 & 0.35 \\
\hline Yes & $190(70.1)$ & $81(29.9)$ & & \\
\hline No & $167(66.3)$ & 85 (33.7) & & \\
\hline
\end{tabular}

(Continued) 
Table 2 (Continued).

\begin{tabular}{|c|c|c|c|c|}
\hline \multirow[t]{2}{*}{ Characteristics } & \multicolumn{2}{|l|}{ Anxiety } & \multirow[t]{2}{*}{$\mathrm{X}^{2}$} & \multirow[t]{2}{*}{ P-value } \\
\hline & $\begin{array}{l}\text { No, n }(\%) \\
(\text { GAD-7score < l } 0)\end{array}$ & $\begin{array}{l}\text { Yes, n (\%) } \\
\text { (GAD-7score } \geq 10)\end{array}$ & & \\
\hline $\begin{array}{l}\text { Are you ready for your future specialty? } \\
\text { Strongly agree } \\
\text { Agree } \\
\text { Neutral } \\
\text { Disagree } \\
\text { Strongly Disagree }\end{array}$ & $\begin{array}{l}26(68.4) \\
78(78.0) \\
180(72.0) \\
41(62.1) \\
32(46.4)\end{array}$ & $\begin{array}{l}12(31.6) \\
22(22.0) \\
70(28.0) \\
25(37.9) \\
37(53.6)\end{array}$ & 22.39 & $<0.001$ \\
\hline $\begin{array}{l}\text { Family problems during study of medicine } \\
\text { Yes } \\
\text { No }\end{array}$ & $\begin{array}{l}89(62.7) \\
268(70.3)\end{array}$ & $\begin{array}{l}53(37.3) \\
113(29.7)\end{array}$ & 2.81 & 0.11 \\
\hline $\begin{array}{l}\text { Financial problems during study of medicine } \\
\text { Yes } \\
\text { No }\end{array}$ & $\begin{array}{l}63(58.3) \\
294(70.8)\end{array}$ & $\begin{array}{l}45(4 \mid .7) \\
121(29.2)\end{array}$ & 6.19 & 0.01 \\
\hline $\begin{array}{l}\text { Social problems during study of medicine } \\
\text { Yes } \\
\text { No }\end{array}$ & $\begin{array}{l}79(56.8) \\
278(72.4)\end{array}$ & $\begin{array}{l}60(43.2) \\
106(27.6)\end{array}$ & $11.4 \mathrm{I}$ & 0.001 \\
\hline $\begin{array}{l}\text { Psychological issues during study of medicine } \\
\text { Yes } \\
\text { No }\end{array}$ & $\begin{array}{l}50(44.6) \\
307(74.7)\end{array}$ & $\begin{array}{l}62(55.4) \\
104(25.3)\end{array}$ & 36.69 & $<0.001$ \\
\hline $\begin{array}{l}\text { Diagnosed with medical problems during study of medicine } \\
\text { Yes } \\
\text { No }\end{array}$ & $\begin{array}{l}49(55.7) \\
308(70.8)\end{array}$ & $\begin{array}{l}39(44.3) \\
127(29.2)\end{array}$ & 7.73 & 0.005 \\
\hline $\begin{array}{l}\text { Diagnosed with psychiatric problems during study of medicine } \\
\text { Yes } \\
\text { No }\end{array}$ & $\begin{array}{l}16(69.6) \\
341(68.2)\end{array}$ & $\begin{array}{l}7(30.4) \\
159(31.8)\end{array}$ & 0.02 & 0.89 \\
\hline
\end{tabular}

Abbreviations: GPA, grade point average; CV, curriculum vitae.

Depression, Anxiety, and Stress Scale 21 (DASS-21) instrument. ${ }^{18}$ El-Gilany et al, who used the HADS as a research instrument found that $38.8 \%$ of male medical students in Egypt had anxiety. ${ }^{19}$ Based on an estimate provided by DASS-21, Yusoff et al reported that $54.5 \%$ of Malaysian medical students had anxiety symptoms. ${ }^{20}$

In line with our findings, a meta-analysis published in 2019 showed that the global prevalence of anxiety among 40,438 medical students from 69 studies was 33.8\% (95\% CI 29.2-38.7). Middle eastern countries showed the highest prevalence compared with other countries. ${ }^{10}$ Another meta-analysis of Brazilian studies revealed that anxiety was prevalent among $32.9 \%$ medical students $(95 \% \mathrm{CI}$ $22.0-44.9) .^{21}$

It is difficult to compare the levels of anxiety in our study with that of Saudi's general population due to the lack of published data in this area. ${ }^{22}$ We could not find a significant association between anxiety and the students' ages. Similarly, no specific age patterns were identified among medical students' levels of anxiety in a large meta-analysis study. ${ }^{10}$ Anxiety was high among females in this study compared to males. Similarly, several studies in KSA, Bahrain, Portugal, Brazil, Pakistan, and Ethiopia showed that anxiety was higher among females. ${ }^{47,17,18,23,24}$ Moreover, this finding has been reported in studies of anxiety disorders among the general population. ${ }^{2}$ Gender differences in the prevalence of anxiety are multifactorial, including cultural, biological, social, or combinations of each. ${ }^{14}$

Since entering medical college is a major transition in students' lives, it could lead to changes in their lifestyles, one of which is their living arrangements. The IAU is a large university in the eastern province of KSA, students from any city in KSA can join it, although it would require them to live away from their families. Our hypothesis that 
Table 3 Multivariable Logistic Regression Analysis of Predictors of Anxiety Symptoms Among the Participating Medical Students

\begin{tabular}{|c|c|c|c|}
\hline Characteristics & Unadjusted OR (95\% Cl) & Adjusted OR (95\% Cl) & Adjusted P-value \\
\hline \multicolumn{4}{|l|}{ Age group (years) } \\
\hline $20-21$ & $1.7(0.8-3.2)$ & $0.7(0.3-2.1)$ & 0.59 \\
\hline $22-23$ & $1.3(0.7-2.4)$ & $1.2(0.5-2.6)$ & 0.68 \\
\hline$\geq 24$ & 1 & I & \\
\hline \multicolumn{4}{|l|}{ Sex } \\
\hline Male & 1 & $\mathrm{I}$ & \\
\hline Female & $2.2(1.5-3.2)$ & $\mathrm{I} .7(\mathrm{I} . \mathrm{I}-2.7)$ & 0.04 \\
\hline \multicolumn{4}{|l|}{ Level in the medical college } \\
\hline Fourth year & $1.6(1.1-2.5)$ & $1.7(0.8-3.4)$ & 0.14 \\
\hline Fifth year & $0.8(0.5-1.3)$ & $0.6(0.3-1.1)$ & 0.09 \\
\hline Sixth year & 1 & 1 & \\
\hline \multicolumn{4}{|l|}{ GPA out of 5} \\
\hline$\leq 3.50$ & $\mathrm{I} .5(0.7-3.4)$ & $1.6(0.6-4.1)$ & 0.33 \\
\hline $3.51-4.00$ & $0.5(0.3-0.9)$ & $0.6(0.3-1.2)$ & 0.13 \\
\hline $4.01-4.50$ & $0.7(0.4-1.3)$ & $0.9(0.5-1.5)$ & 0.61 \\
\hline$>4.51$ & 1 & 1 & \\
\hline \multicolumn{4}{|l|}{ Did you choose you future specialty? } \\
\hline Yes & 1 & I & \\
\hline No & I.I (0.8-I.6) & $0.8(0.5-1.2)$ & 0.28 \\
\hline Not willing to have any & $2.6(0.9-7.0)$ & $2.1(0.7-6.4)$ & 0.21 \\
\hline \multicolumn{4}{|l|}{ Are you ready for your future specialty? } \\
\hline Strongly agree & 1 & 1 & \\
\hline Agree & $0.6(0.3-1.4)$ & $0.6(0.2-1.5)$ & 0.27 \\
\hline Neutral & $0.8(0.4-1.8)$ & $0.8(0.4-1.8)$ & 0.58 \\
\hline Disagree & $1.3(0.6-3.1)$ & I.I $(0.4-3.0)$ & 0.78 \\
\hline Strongly Disagree & $2.5(1.1-5.8)$ & $2.1(0.9-5.5)$ & 0.13 \\
\hline \multicolumn{4}{|l|}{ Family problems during study of medicine } \\
\hline Yes & $1.4(0.9-2.1)$ & $1.2(0.7-1.8)$ & 0.56 \\
\hline No & 1 & 1 & \\
\hline \multicolumn{4}{|l|}{ Financial problems during study of medicine } \\
\hline Yes & $1.7(1.1-2.7)$ & $1.2(0.7-2.1)$ & 0.51 \\
\hline No & 1 & I & \\
\hline \multicolumn{4}{|l|}{ Social problems during study of medicine } \\
\hline Yes & $2.0(1.3-3.0)$ & $1.5(0.9-2.4)$ & 0.13 \\
\hline No & 1 & I & \\
\hline \multicolumn{4}{|l|}{ Psychological issues during study of medicine } \\
\hline Yes & $3.7(2.4-5.6)$ & $3.1(1.8-5.2)$ & $<0.001$ \\
\hline No & 1 & I & \\
\hline \multicolumn{4}{|l|}{ Diagnosed with medical problems during study of medicine } \\
\hline Yes & $1.9(1.2-3.1)$ & $1.2(0.7-2.1)$ & 0.57 \\
\hline No & 1 & I & \\
\hline
\end{tabular}

Abbreviations: GPA, grade point average; OR, odds ratio; $\mathrm{Cl}$, confidence interval.

students who lived away from their families had higher levels of anxiety symptoms was not confirmed. Similar findings were reported by Brenneisen Mayer et al in
Brazilian medical students. ${ }^{23}$ We could not find a significant association between anxiety and students' GPA. Similar findings were reported in a study conducted 
in Portugal. ${ }^{4}$ Since high GPA was not the only requirement for getting accepted in Saudi Arabia's national residency programs; it may have lessened the stress and anxiety of students to achieve a high GPA. ${ }^{13}$

Student self-perceived readiness for their future specialty was associated with anxiety, most students with anxiety symptoms thought that they were not ready for future specialty. In line with this finding, most students with anxiety were in the fourth-year level in the medical college in which they just started their clinical rotations. This could be explained by that students in the fourth year, although have more time to start working with the requirements for their future career, they still have not been exposed to most specialties and eventually may not start preparing themselves for their future career. Moreover, there have been reports in the literature revealing that anxiety was high among students at the start of their clinical years where they are exposed to sick patients. ${ }^{7,9}$ However, the association of anxiety with students' levels of study and their self-perceived readiness for specialty became insignificant after the regression analysis.

In the current study, anxiety was not associated with students' research participation and their CV preparation. However, a considerable number of medical students in the study reported that they had not prepared their CV. Moreover, about half of the students did not participate in any research project. Abulaban et al, who conducted a study in 2015 among 924 medical students from five Saudi universities found that $53.4 \%$ of the students had not participated in research during the undergraduate period, although $98.1 \%$ of them had the interest to participate in research, if they had the opportunity. ${ }^{25}$ Participation in research is crucial for medical students during the undergraduate period in KSA since it is factored in their CV and consequently affects their entry into competitive residency programs. ${ }^{13}$ To help students in their research, support and guidance from the university's research department and faculties are highly mandated.

Challenges and stressors that could be faced by medical students during their journey in the medical school have been studied in the literature, and their link with student's mental health was reported. Financial burden, failure in medical school, problems in the family, having chronic medical problems, emotional failure, stressful life events, and social pressures all were reported to be associated with high levels of anxiety among medical students. ${ }^{24,26,27}$ Similarly, the rates of anxiety symptoms in the current study were higher among students who had financial, social, psychological, and medical problems since admission to the university. Although these factors were addressed in the current study based on selfprecepted questions as defined by students themselves and this has been included in the limitation of the study, this finding is alarming for the policymaker and addressing these issues in medical students is crucial. However, after controlling the confounding effects in the multivariable regression analyses, having psychological problems was the only independent factor associated with anxiety in our study.

In this study, only $4.4 \%$ students went to healthcare professionals and were diagnosed with psychiatric problems. This worrying finding has also been reported in several other studies. For example, in Portugal, approximately $60 \%$ of college students with anxiety never went to healthcare professionals to seek mental health advice. ${ }^{4}$ A possible explanation for this finding in our study could be that seeking psychological counselling was sometimes considered a sensitive issue in some Arab cultures, and visiting mental health professionals could lead to stigmatization in some Middle Eastern cultures. ${ }^{7,10}$ Furthermore, although participation in the study was voluntary, and anonymity and confidentiality were maintained, underreporting of true prevalence might have been another possible reason, as some students might have been uncomfortable about reporting their psychiatric diagnosis. ${ }^{7}$ Moreira de Sousa et al reported that Portuguese students may accept anxiety symptoms as being a normal part of their academic lives and did not seek medical advice. Moreover, fear of stigmatization, self-diagnosis, and selfprescribed medications, all of which are possible barriers to visit mental health professionals. ${ }^{4}$

While the present study has some limitations, it also has several strengths. It is one of the few studies conducted in KSA to examine the prevalence of anxiety symptoms among medical students. Additionally, no prior study has been conducted to evaluate the association between anxiety and the preparation of medical students for their future specialties. The curriculum at the College of Medicine at Saudi Arabia's IAU has been subjected to continuous evaluation since its establishment in 1975. The revised study plan that was launched in 2014 facilitated moving from traditional modulebased education to a problem-based approach, in which students discuss case scenarios from the first year itself. ${ }^{8}$ In this study, we targeted clinical-yeas students who were the first three batches of the new curriculum. Nonetheless, we acknowledge some limitations. For example, the single institution used in the current study might have limited the generalizability of the results. Moreover, as the survey was self- 
administered, we could not exclude the risk of recall bias. A further potential limitation may be self-perception of familial, financial, social, and psychological problems, which could be addressed further using a qualitative method.

\section{Conclusion}

The high prevalence of anxiety in medical students in the current study is worrying. Although anxiety symptoms were more among female students and those who perceived that they had psychological problems, the students who chose to seek professional help for their psychological health were the minority. This encourages establishing periodic mental health screening programs for medical students, providing early diagnosis of high-risk individuals, and early interventions through confidential access to mental health services. No relationships were reported between anxiety symptoms and students' GPA as well as their perceived readiness for future specialties. Furthermore, the minority of students in this study thought that they were ready for their future specialty. This suggests the need to launch proper faculty mentorship programs that would train university faculties on how to guide medical students in choosing their future careers and help these students in preparing themselves with the requirements. Moreover, qualitative studies to explore the associations between anxiety and other factors in students such as their temperaments, lifestyle, sleeping patterns and deprivation are suggested.

\section{Abbreviations}

WHO, World Health Organization; GAD, Generalized anxiety disorder; GPA, Grade Point Average; CV, Curriculum Vitae; IAU, Imam Abdulrahman Bin Faisal University.

\section{Ethics Approval}

The IRB committee at IAU approved the study. All participants gave their written consent. The researcher explained to the participants the study purpose, and to reassure them that there was no negative impact on them. Confidentiality of the data was assured, and it will be used only for research purposes.

\section{Acknowledgments}

The authors would like to thank the following medical students who participated in the data collection: Afnan A Alqutub, Fahad A Alzahrani, Kawthar A Alabdrabalrasol, Maan A Albehair, Majd M Alrayes, Mazen A Alosail, Mohammed A Aldokhi, Naif M Albluwi and Omar Y Almukhadhib. Also, we would like to thank Editage for English language editing. The authors would like to thank students who participated in the study. The content is under the responsibility of the researchers and does not represent the views of Imam Abdulrahman Bin Faisal University.

\section{Disclosure}

The authors report no conflicts of interest in this study.

\section{References}

1. World Health Organization. Mental Health Action Plan 2013-2020. Geneva: world Health Organization; 2013. Available from: http:// apps.who.int/iris/bitstream/10665/89966/1/9789241506021_eng.pdf. Accessed October 11, 2018.

2. World Health Organization. Depression and Other Common Mental Disorders: Global Health Estimates. Geneva:World Health Organization. Licence: CC BY-NC-SA 3.0 IGO. 2017.

3. American Psychiatric Association. Diagnostic and Statistical Manual of Mental Disorders. 5th ed. Arlington, Va.: American Psychiatric Association;2013.

4. Moreira de Sousa J, Moreira CA, Telles-Correia D. Anxiety, depression and academic performance: a study amongst portuguese medical students versus non-medical students. Acta Med Port. 2018;31 (9):454-462. doi:10.20344/amp.9996

5. Mousa OY, Dhamoon MS, Lander S, Dhamoon AS. The MD blues: under-recognized depression and anxiety in medical trainees. PLoS One. 2016;11(6):e0156554. doi:10.1371/journal.pone.0156554

6. Maser B, Danilewitz M, Guérin E, Findlay L, Frank E. Medical student psychological distress and mental illness relative to the general population: a canadian cross-sectional survey. Acad Med. 2019;94(11):1781-1791. doi:10.1097/ACM.0000000000002958

7. Mahroon ZA, Borgan SM, Kamel C, Maddison W, Royston M, Donnellan C. Factors associated with depression and anxiety symptoms among medical students in Bahrain. Acad Psychiatry. 2018;42 (1):31-40. doi:10.1007/s40596-017-0733-1

8. AlShamlan NA, Al Shammari MA, Darwish MA, Sebiany AM, Sabra AA, Alalmaie SM. Evaluation of multifaceted assessment of the fifth-year medical students in family medicine clerkship, Saudi Arabia experience. J Multidiscip Healthc. 2020;13:321-328. doi:10. 2147/JMDH.S241586

9. Kulsoom B, Afsar NA. Stress, anxiety, and depression among medical students in a multiethnic setting. Neuropsychiatr Dis Treat. 2015;11:1713-1722. doi:10.2147/NDT.S83577

10. Tian-Ci Quek T, Tam WS, X Tran B, et al. The global prevalence of anxiety among medical students: a meta-analysis. Int J Environ Res Public Health. 2019;16(15):2735. doi:10.3390/ijerph16152735

11. Wahed WY, Hassan SK. Prevalence and associated factors of stress, anxiety and depression among medical Fayoum University students. Alexandria J Med. 2017;53(1):77-84. doi:10.1016/j.ajme.2016.01. 005

12. Talih F, Daher M, Daou D, Ajaltouni J. Examining burnout, depression, and attitudes regarding drug use among Lebanese medical students during the 4 years of medical school. Academic Psychiatr. 2018;42:288-296. doi:10.1007/s40596-017-0879-x

13. Saudi commission for health specialities. Saudi Commision for Health Specialties Matching System Princibles and Guidelines. SCFHS. 2020.Available from: https://www.scfhs.org.sa/MESPS/ Documents/MS\%20Book-English.pdf

14. M AT A, Saddichha S, Al Malki S, et al. Depression and anxiety among Saudi university students: prevalence and correlates. Arab J Psychiatr. 2013;24:1. doi:10.12816/0000092 
15. Spitzer RL, Kroenke K, Williams JB, Lowe B. A brief measure for assessing generalized anxiety disorder: the GAD-7. Arch Intern Med. 2006;166(10):1092-1097. doi:10.1001/archinte.166.10.1092

16. Samaranayake CB, Fernando AT. Satisfaction with life and depression among medical students in Auckland, New Zealand. Clin Correspondence. 2011;26.

17. Azad N, Shahid A, Abbas N, Shaheen A, Munir N. Anxiety and depression in medical students of a private medical college. J Ayub Med Coll Abbottabad. 2017;29(1):123-127.

18. Bahhawi TA, Albasheer OB, Makeen AM, et al. Depression, anxiety, and stress and their association with khat use: a cross-sectional study among Jazan University students, Saudi Arabia. Neuropsychiatr Dis Treat. 2018;14:2755-2761. doi:10.2147/NDT.S182744

19. El-Gilany AH, Amr M, Hammad S. Perceived stress among male medical students in Egypt and Saudi Arabia: effect of sociodemographic factors. Ann Saudi Med. 2008;28(6):442-448. doi:10.5144/ 0256-4947.2008.442

20. Yusoff MS, Abdul Rahim AF, Baba AA, Ismail SB, Pa MN M, Esa AR. Prevalence and associated factors of stress, anxiety and depression among prospective medical students. Asian J Psychiatr. 2013;6(2):128-133. doi:10.1016/j.ajp.2012.09.012

21. Pacheco JP, Giacomin HT, Tam WW, et al. Mental health problems among medical students in Brazil: a systematic review and meta-analysis. Braz J Psychiatr. 2017;39(4):369-378. doi:10.1590/ 1516-4446-2017-2223
22. Aboalshamat K, Hou XY, Strodl E. Psychological well-being status among medical and dental students in Makkah, Saudi Arabia: a cross-sectional study. Med Teach. 2015;37(Suppl 1):S75-81. doi:10. 3109/0142159X.2015.1006612

23. Brenneisen Mayer F, Souza Santos I, Silveira PS, et al. Factors associated to depression and anxiety in medical students: a multicenter study. BMC Med Educ. 2016;16(1):282. doi:10.1186/ s12909-016-0791-1

24. Kebede MA, Anbessie B, Ayano G. Prevalence and predictors of depression and anxiety among medical students in Addis Ababa, Ethiopia. Int J Ment Health Syst. 2019;13:30. doi:10.1186/s13033019-0287-6

25. Abulaban A, Alharbi A, BinDajam O, et al. Changing opinions about research by Saudi medical students. Adv Med Educ Pract. 2017;8:571-575. doi:10.2147/AMEP.S127853

26. Fawzy M, Hamed SA. Prevalence of psychological stress, depression and anxiety among medical students in Egypt. Psychiatr Res. 2017;255:186-194. doi:10.1016/j.psychres.2017.05.027

27. Ibrahim N, Al-Kharboush D, El-Khatib L, Al-Habib A, Asali D. Prevalence and predictors of anxiety and depression among female medical students in King Abdulaziz University, Jeddah, Saudi Arabia. Iran J Public Health. 2013;42(7):726-736.

\section{Publish your work in this journal}

The Journal of Multidisciplinary Healthcare is an international, peerreviewed open-access journal that aims to represent and publish research in healthcare areas delivered by practitioners of different disciplines. This includes studies and reviews conducted by multidisciplinary teams as well as research which evaluates the results or conduct of such teams or healthcare processes in general. The journal covers a very wide range of areas and welcomes submissions from practitioners at all levels, from all over the world. The manuscript management system is completely online and includes a very quick and fair peer-review system. Visit http://www.dovepress.com/testimonials. php to read real quotes from published authors. 